\title{
Pollen development in Annona cherimola Mill. (Annonaceae). Implications for the evolution of aggregated pollen Jorge Lora1, Pilar S Testillano ${ }^{2}$, Maria C Risueño ${ }^{2}$, Jose I Hormaza*1 and Maria Herrero ${ }^{3}$
}

\author{
Address: ${ }^{1}$ Estación Experimental "La Mayora", CSIC, 29760 Algarrobo-Costa, Málaga, Spain, ${ }^{2}$ Centro de Investigaciones Biológicas, CSIC, Ramiro \\ de Maeztu 9, 28040, Madrid, Spain and 32Dep. Pomología, Estación Experimental "Aula Dei", CSIC, Apdo. 202/50080 Zaragoza, Spain \\ Email: Jorge Lora - jlora@eelm.csic.es; Pilar S Testillano - testillano@cib.csic.es; Maria C Risueño - risueno@cib.csic.es; \\ Jose I Hormaza* - ihormaza@eelm.csic.es; Maria Herrero - mherrero@eead.csic.es \\ * Corresponding author
}

Published: 29 October 2009

BMC Plant Biology 2009, 9:129 doi:10.1 186/147|-2229-9-129
Received: 14 April 2009

Accepted: 29 October 2009

This article is available from: http://www.biomedcentral.com/I47I-2229/9//29

(c) 2009 Lora et al; licensee BioMed Central Ltd.

This is an Open Access article distributed under the terms of the Creative Commons Attribution License (http://creativecommons.org/licenses/by/2.0), which permits unrestricted use, distribution, and reproduction in any medium, provided the original work is properly cited.

\begin{abstract}
Background: In most flowering plants, pollen is dispersed as monads. However, aggregated pollen shedding in groups of four or more pollen grains has arisen independently several times during angiosperm evolution. The reasons behind this phenomenon are largely unknown. In this study, we followed pollen development in Annona cherimola, a basal angiosperm species that releases pollen in groups of four, to investigate how pollen ontogeny may explain the rise and establishment of this character. We followed pollen development using immunolocalization and cytochemical characterization of changes occurring from anther differentiation to pollen dehiscence.
\end{abstract}

Results: Our results show that, following tetrad formation, a delay in the dissolution of the pollen mother cell wall and tapetal chamber is a key event that holds the four microspores together in a confined tapetal chamber, allowing them to rotate and then bind through the aperture sites through small pectin bridges, followed by joint sporopollenin deposition.

Conclusion: Pollen grouping could be the result of relatively minor ontogenetic changes beneficial for pollen transfer or/and protection from desiccation. Comparison of these events with those recorded in the recent pollen developmental mutants in Arabidopsis indicates that several failures during tetrad dissolution may convert to a common recurring phenotype that has evolved independently several times, whenever this grouping conferred advantages for pollen transfer.

\section{Background}

Pollen development is a well characterized and highly conserved process in flowering plants [1-3]. Typically, following anther differentiation, a sporogenous tissue develops within the anthers producing microsporocytes or pollen mother cells. Prior to meiosis, pollen mother cells become isolated by a wall with the deposition of a callose layer. Each pollen mother cell, as the result of the two mei- otic divisions, generates four haploid cells forming a tetrad and, for a short time, these four sibling microspores are held together in a persistent pollen mother cell wall that is surrounded by callose. The tapetum then produces an enzyme cocktail that dissolves the pollen mother cell wall and the microspores are shed free and become independent [2]. The unicellular microspores go through an asymmetric mitotic division (pollen mitosis I) to produce 
a pollen grain with two cells, a larger vegetative cell that hosts a smaller generative cell; the latter will divide once more to produce two sperm cells (Pollen mitosis II). Pollen mitosis II can take place before or after pollen release and, depending on when it occurs, the pollen will be bicellular or tricellular at the time of anther dehiscence. Throughout the manuscript we will use the term "pollen tetrads" for mature pollen to avoid confusion with the tetrads of early developmental stages ("microspore tetrads").

Angiosperms pollen is most commonly released as single pollen grains or monads [4] which represent the basic angiosperm pollen-unit. Dehiscence of aggregated pollen (mostly in groups of four) is considered a recent apomorphic characteristic $[5,6]$ that has arisen independently several times during evolution primarily in animalpollinated taxa although, in some cases, monads may have evolved secondarily from groups of four grains [6]. Pollen release as tetrads has been reported in some or all members of 55 different angiosperm families and also in some pteridophytes [7]. Blackmore and Crane (1988) [8] put forward that the maintenance of pollen tetrads could be the result of relatively minor ontogenetic changes and, consequently, this could be an excellent example of convergence in situations where the release of pollen as tetrads is an effective reproductive strategy. Interestingly, the dissemination of pollen as tetrads has also been reported in the quartet mutants of Arabidopsis $[9,10]$.

Annonaceae, included in the order Magnoliales, is the largest family within the basal angiosperm Magnoliid clade $[11,12]$. Due to its phylogenetic position among the basal angiosperms, the family has been the object of considerable interest from a taxonomic and phylogenetic point of view [13-15] and a number of studies have focused on pollen morphology [16-20]. Although most genera of the Annonaceae produce solitary pollen at maturity, in several species of the family pollen is released aggregated in groups of four or in polyads [17]. Recent studies on the mechanism of pollen cohesion in this family have been performed in species of the genera Pseuduvaria [21], Annona and Cymbopetalum [22,23]. Pollen cohesion in these species is generally acalymmate (four pollen grains are grouped only by partial fusion) with simple cohesion [21]. But these studies show differences in cohesion mechanisms; thus, while pollen grains in Pseuduvaria are connected by wall bridges (crosswall cohesion), involving both the exine and the intine, in A. glabra, A. montana and Cymbopetalum cohesion is achieved through a mass of callose-cellulose. Evolutionary transitions in flowering plant reproduction are proving to have a clear potential in plant evolutionary biology [24], and the need for more detailed ontogenetic studies in the family has been put forward [22]. Indeed the fact of being the largest family among basal angiosperms, together with the puzzling connection mechanisms so far described in the different species examined, provide an excellent opportunity to investigate the ontogeny of pollen development and its evolutionary implications.

In this work, pollen development is characterized in $A$. cherimola, one of the species in the Annonaceae where pollen is shed aggregated in groups of four, paying special attention to the events close to pollen formation and retention of the individual pollen grains together, observed by immunolocalization of different wall components. Results are discussed in relation to the shedding of pollen in groups of four in other species and how this event may have occurred and settled during evolution.

\section{Results}

The mature A. cherimola flower is a syncarpous gynoecium with a conic shape composed of about 100 fused carpels surrounded at its base by several rows of anthers with up to 200 stamens, encircled by two whorls of three petals. The flower cycle from opening to anther dehiscence lasts two days: the flower opens on the morning of the first day in the female stage and remains in this stage until the afternoon of the following day when the flower enters the male stage. Anther dehiscence occurs concomitantly in all stamens of a flower and, as the anthers dehisce, they detach from the flower and fall over the open petals.

Flower buds of A. cherimola develop in the leaf axes following leaf expansion; the basal nodes are differentiated in the year preceding anthesis. The uppermost distal buds differentiate in synchrony with shoot growth [25]. Flower bud growth begins 39 days prior to anthesis. Anther differentiation proceeded centripetally, with the most developmentally advanced anthers placed in the outermost rows and the different stages of anther and pollen development present within the same flower. This fact was helpful for establishing successive stages of anther development. The anther becomes septate with pollen mother cells positioned between rows of interstitial tapetum similar to the anthers described in a sister species, Annona squamosa [26].

To determine if pollen development followed a standard pattern and whether pollen tetrads at anther dehiscence corresponds with the cytological and morphological features of mature pollen, anther and pollen development were examined from microsporogenesis to maturity. Special attention was given to the events responsible for pollen cohesion. Microgametogenesis and tapetum degeneration were also examined sequentially.

\section{Microsporogenesis}

Initial hypodermal archesporial cells were apparent 24 days before anthesis (Figure 1A). From them, anther septa 


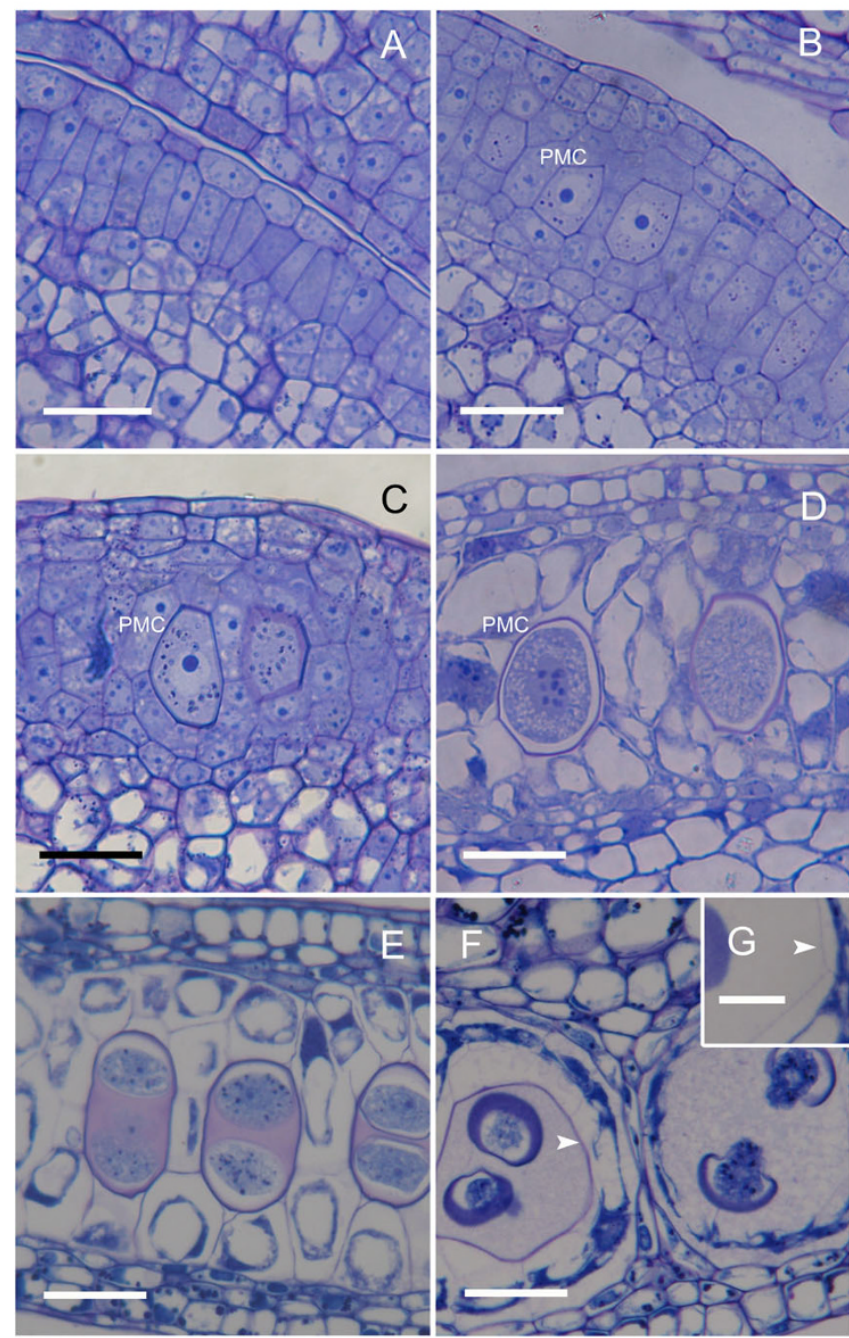

\section{Figure I}

Microsporogenesis of Annona cherimola. (A) Uniseriate row of arquesporial cells. (B) Septal and pollen mother cells (PMC), showing a conspicuous wall, alternate in the sporogenous tissue. (C) PMC increase in size and starch grains are visible. (D) Starch grains vanish, a translucent layer appears in the PMC wall, and PMC starts meiosis. The tapetum vacuolates and the tapetal chambers are apparent. (E) Following meiosis, starch grains accumulate again in the young microspores, which are surrounded by callose. $(F)$ The young microspores, with an incipient exine, appear to float and turn within the still remaining PMC wall (arrow) that holds the four microspores together. (G) Detail of PMC wall (arrow). Longitudinal sections of the anthers stained with PAS and Toluidine blue. Bar $=20 \mu \mathrm{m}$.

initials and pollen mother cells (PMC) developed in $9 \mathrm{~cm}$ long flower buds 19 days before anthesis (Figure 1B). Each anther contained a uniseriate row of pollen mother cells with a conspicuous common wall. The PMC began to accumulate starch grains (Figure 1C) and increased in size

(Figure 1C, 1D). Starch grains vanished concomitantly with the beginning of meiosis, some 15 days before anthesis, as a translucent cell wall layer was apparent surrounding the PMC (Figure 1D). Meiosis proceeded rapidly and was followed by a new accumulation of starch grains in the young microspores (Figure 1E) 14 days before anthesis. The microspore tetrads remained together in isolated tapetal chambers surrounded by the PMC wall that stained positively with periodic acid-Shiff's reagent (PAS) for carbohydrates (Figure 1F, 1G).

Immunocytochemical essays revealed the localization of various cell wall components (Figure 2). Callose surrounded the PMC wall and, following meiosis I, an additional furrow of callose developed inwards (Figure 2A) forming a callose positive band between the dyad cells (Figure 2B, 2C). Successive cytokinesis followed (Figure 2C), resulting in a tetrad (2D), each separated by callose. Dyad and tetrad stages coexist in the flower as centripetal maturation progresses. The PMC wall also reacted positively to JIM7 (Figure 2E) and JIM5 (Figure 2F) staining, indicating the presence of methyl-esterified and unesterified pectins respectively. However, while the walls of the anther somatic and tapetal cells also reacted positively to the JIM7 for methyl-esterified pectins (Figure 2E), they
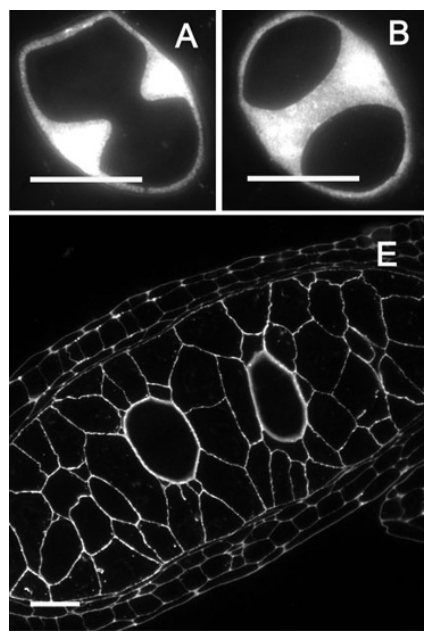

E

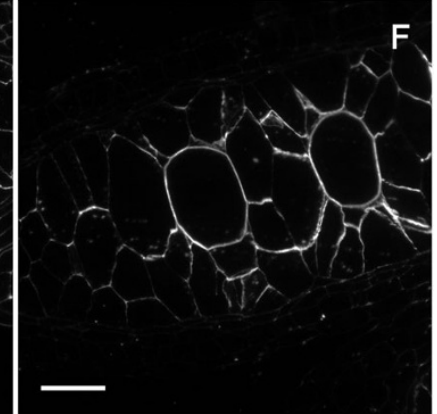

Figure 2

Callose and pectins during microsporogenesis in Annona cherimola. (A-D) Anticallose in dyad/tetrad phases. (A) A furrow of callose developed inwards, forming a wall between the dyad cells. (B) Dyad phase, showing (B) an incipient, and (C) a well developed callose wall. (D) Tetrad microspore showing in the section plane three of the microspores separated by callose walls. (E) PMC and other anther tissue walls showing methyl-esterified pectins. (F) PMC wall also shows unesterified pectins. Specific cell components were localized using antibodies against callose $(A, B, C, D)$, methylesterified pectin (JIM7) (E), and unesterified pectin (JIM5) (F). A-D Bar $=10 \mu \mathrm{m}$. E-F: Bar $=20 \mu \mathrm{m}$. 
showed only a faint staining for the presence of unesterified pectins (Figure 2F).

\section{Pollen cohesion}

Following tetrad formation, callose disappeared but the microspores remained within the PMC calcofluor-positive cellulosic wall (Figure 3A). At this developmental stage, an interesting event was detected: the microspores within each tapetal chamber, which initially had their pollen aperture sites facing outward towards the PMC wall (Figure $3 \mathrm{~A}$ ), appeared to float and rotate within their individual chambers (Figure 3B). This movement was not random, but the microspores turned $180^{\circ}$ until the pollen aperture sites faced each other (Figure 3B). The remaining PMC cellulosic wall, which persisted for some time, together with the confined space provided by the tapetal chamber, appear to contribute towards keeping the microspore tetrad together. Subsequently the PMC cellulosic wall disappeared completely (Figure 3C) and the tapetum degenerated as the microspores increased in size. They
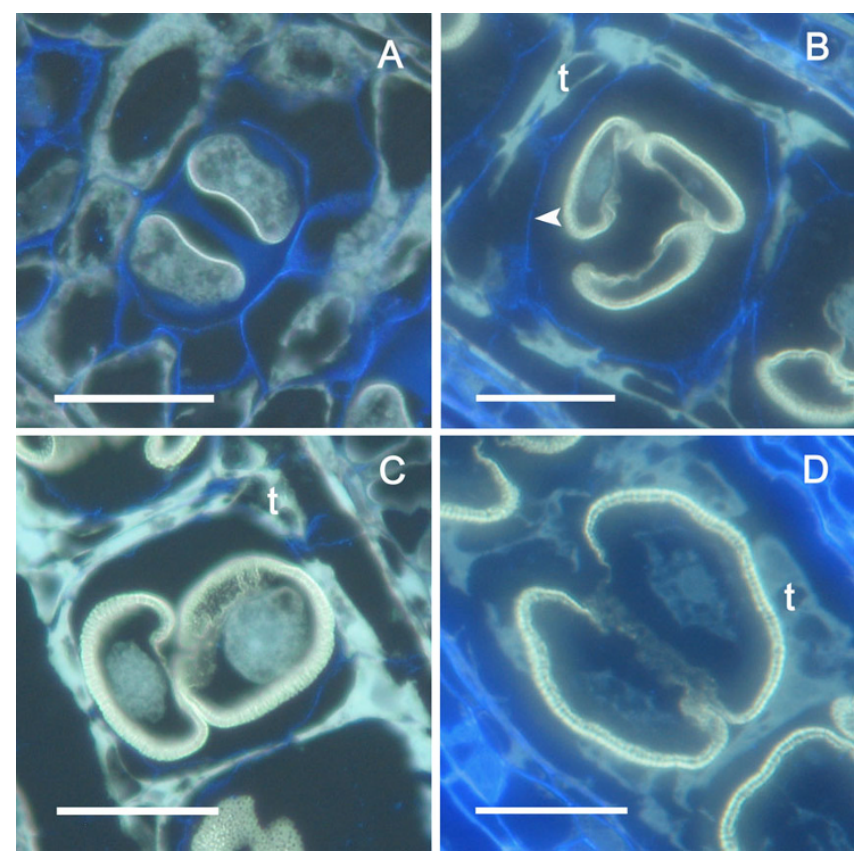

Figure 3

Pollen development within the tapetal chamber in Annona cherimola. (A) Two young microspores in a tetrad which still keeps the pollen mother cell wall. Aperture sites are located towards the outside facing the pollen mother cell wall. (B) Pollen is shed free, within the PMC wall, in the tapetal chamber. Within this confined space the young microspores turn $(C)$ with their aperture sites facing now each other as the PMC cellulosic wall is digested. (D) The pollen grains regroup sticking through the aperture sites, and enlarge as the tapetum degenerates. Longitudinal anther 2 $\mu \mathrm{m}$ resin sections stained with calcofluor and auramine. Bar $=20 \mu \mathrm{m}$. remained in their new orientation attached by their apparently sticky aperture sites that now faced each other (Figure 3D).

At this stage, both the cell walls of the somatic cells of the anther and the inner wall of microspores (intine) reacted similarly for methyl-esterified pectins (Figure 4A), while unesterified pectins were present just in the microspore intine (Figure 4B). The exine showed a low unspecific

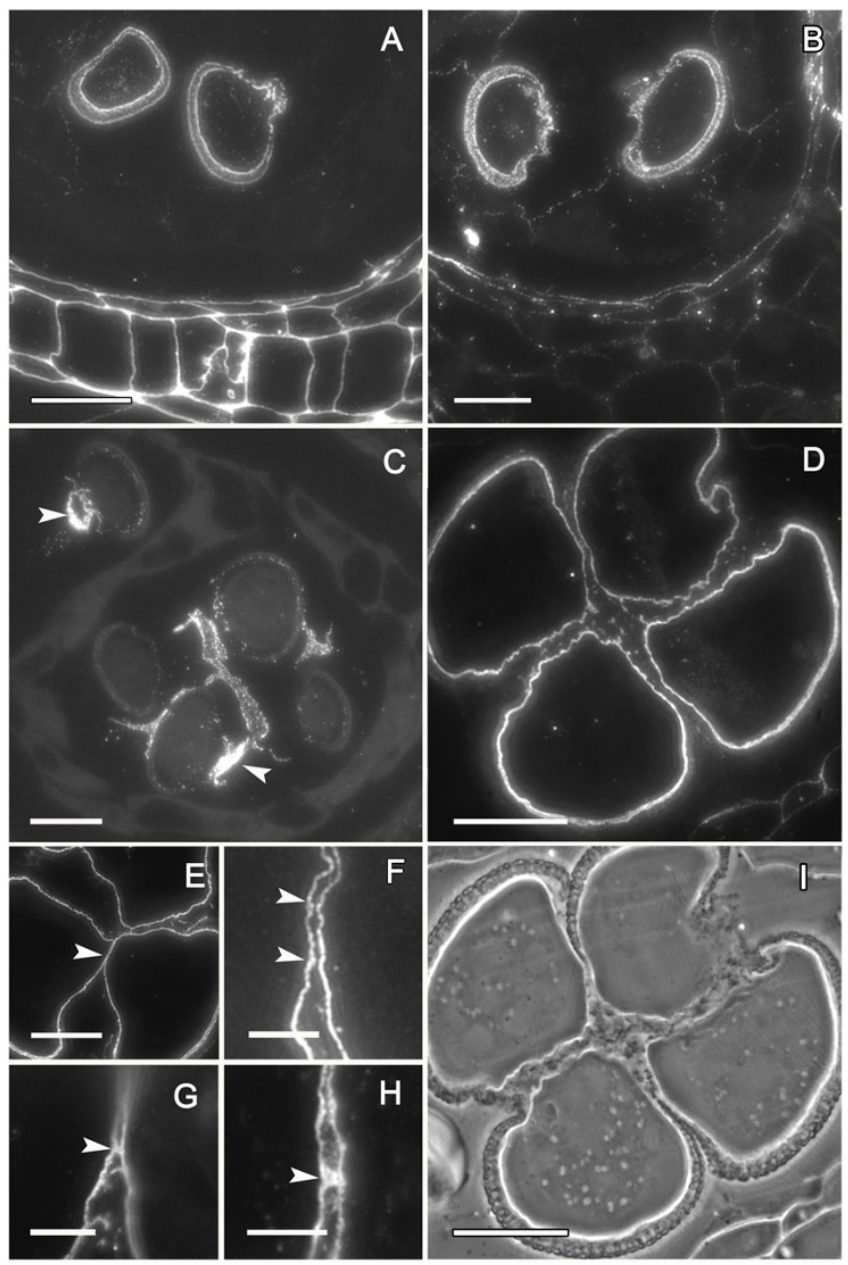

\section{Figure 4}

Establishment of pollen cohesion in Annona cherimola. (A) Microspore walls show methyl-esterified pectins, and also (B) unesterified pectins. (C) As callose is digested, remnants of callose (white arrow) are observed layering the pollen aperture sites. (D-F) Microspores show crosswall cohesion bridges showing the presence of unesterified pectins. (G-H) Details of crosswall cohesion bridges, showing the presence of methyl-esterified pectins. (I) Phase contrast of a mature pollen grain showing internal cohesion and a joint sporopollenin layering. Specific cell components were localized using antibodies against: methyl-esterified pectin (JIM7) (A, G-H), unesterified pectin (JIM5) (B, D, E, F) Callose (C). A-E, I: Bar $=10 \mu \mathrm{m}$. F-H: Bar $=3 \mu \mathrm{m}$. 
autofluorescence but in a different fluorescence wavelength (yellowish color) than the fluorescent marker of the antibodies, AlexaFluor 488, which emitted green fluorescence. As a consequence, exine autofluorescence was clearly differentiated from the immunofluorescence signals. Anti-callose immunofluorescence revealed remnants of callose at the pollen aperture sites where the thick external layer of the microspore wall, the exine, was extremely thin or absent. These callose remnants were apparent in all microspores at this stage (Figure 4C). The four microspores showed crosswall cohesion bridges that stained with antibodies against unesterified and methyl-esterified pectins in the microspore wall (Figure 4D-H). Following this inter-intine cohesion, additional deposition of sporopollenin with a joint layering of the four microspores further strengthened this connection (Figure 4I).

\section{Microgametogenesis}

As the microspores increased in size, their cytoplasm became vacuolated (Figure 5A) and starch grains were absent (Figure 5B). During this vacuolization, nuclear
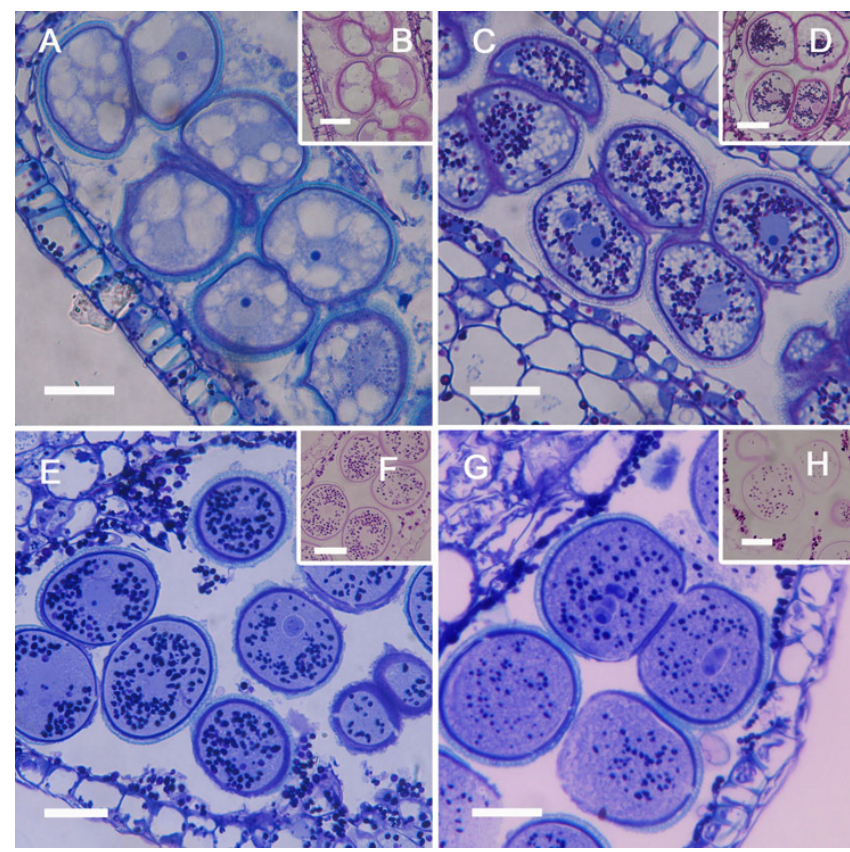

\section{Figure 5}

Microgametogenesis in Annona cherimola. (A) Microspores increase in size as vacuoles appear in the cytoplasm, (B) microspores at this stage do not have starch grains. (C) Microspores following mitosis I; (D) as vacuoles decrease in size, starch grains are stored. (E) Young pollen grains without vacuoles $(F)$, which accumulated starch grains. (G) Close to the time of anther dehiscence, the second mitosis occurs, the tapetum is completely degenerated and $(\mathrm{H})$ starch is digested. Longitudinal sections of anthers stained with PAS and Toluidine blue (A, C, E, G), and with PAS (B, D, F, H) to show starch grains. Bar $=20 \mu \mathrm{m}$. migration preceded the first mitosis to form bicellular pollen grains. Following the first mitosis, 4-6 days before anthesis, the vacuoles decreased in size (Figure 5C) and starch was again stored (Figure 5D). Young pollen grains had no vacuoles (Figure 5E) and numerous starch grains were present (Figure 5F). The second mitotic division producing the first tricellular pollen grains started some four hours prior to anther dehiscence (Figure 5G) and one day prior to anther dehiscence starch grains began to hydrolyze (Figure 5H). Mitotic divisions were not synchronized within a pollen tetrad and single pollen grains with different numbers of nuclei could be observed in the same tetrad resulting in the coexistence of bicellular and tricellular pollen upon anther dehiscence.

In mature pollen, while intine thickness was similar around the pollen grain, the exine was thinner or absent at the pollen aperture sites where contact points between sibling pollen grains were established (Figure 6A). At
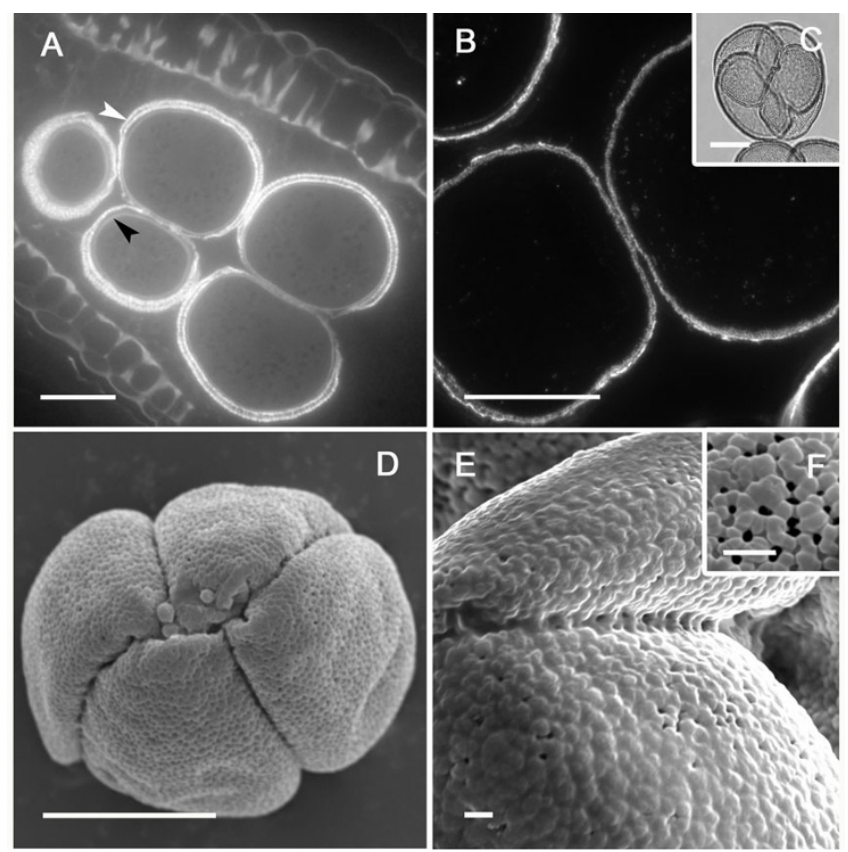

\section{Figure 6}

Mature pollen of Annona cherimola. (A) Intine (black arrow) is similar all around the pollen grain, but exine (white arrow) is thinner in the pollen aperture site. Longitudinal section stained with a 3:I mixture of Auramine and Calcofluor. (B) Sibling pollen grains have a faint cohesion that showed with JIM 5 antibody the presence of unesterified pectins. (C) Mature pollen tetrad following acetolysis. (D, E, F) Mature pollen observed with scanning electron microscopy (SEM). (D) Mature pollen grains with a globose shape and a radiosymmetric disposition. (E) Exine cohesion helps keeping sibling pollen grains together. $(F)$ Pollen exine shows a tectate perforate appearance. A, B, D: Bar $=20 \mu \mathrm{m}$; C: Bar $=10 \mu \mathrm{m} ; \mathrm{E}, \mathrm{F}: \mathrm{Bar}=2 \mu \mathrm{m}$. 
these areas unesterified and methyl-esterified pectin bridges were maintained throughout pollen development although these connections seemed to be less strong in mature pollen (Figure 6B). However, mature pollen tetrads resisted separation during acetolysis, showing the permanence of joint sporopollenin (Figure 6C).

Scanning electron micrographs revealed that mature pollen had a radiosymetric globose shape, was inaperturated, tectate perforate, and with a diameter of $40 \mu \mathrm{m}$ (Figure $6 \mathrm{D}, 6 \mathrm{E}, 6 \mathrm{~F}$ ). Mature pollen was shed in groups of four sibling pollen grains that stick together having an exine cohesion, clearly visible with high magnification scanning electron microscopy images (Figure 6E).

\section{Tapetum degeneration}

A. cherimola has a secretory tapetum with tapetal-type septa similar to those described in other species of the genus Annona such as A. squamosa [26] and A. glabra [27]. Prior to meiosis, septal initials formed tapetal chambers that host the PMC (Figure 7A). After meiosis, the tapetum showed a vacuolization and a progressive degeneration as the tapetal chamber enlarged (Figure 7B). The nuclei of the tapetal cells displayed elongated and lobular shapes
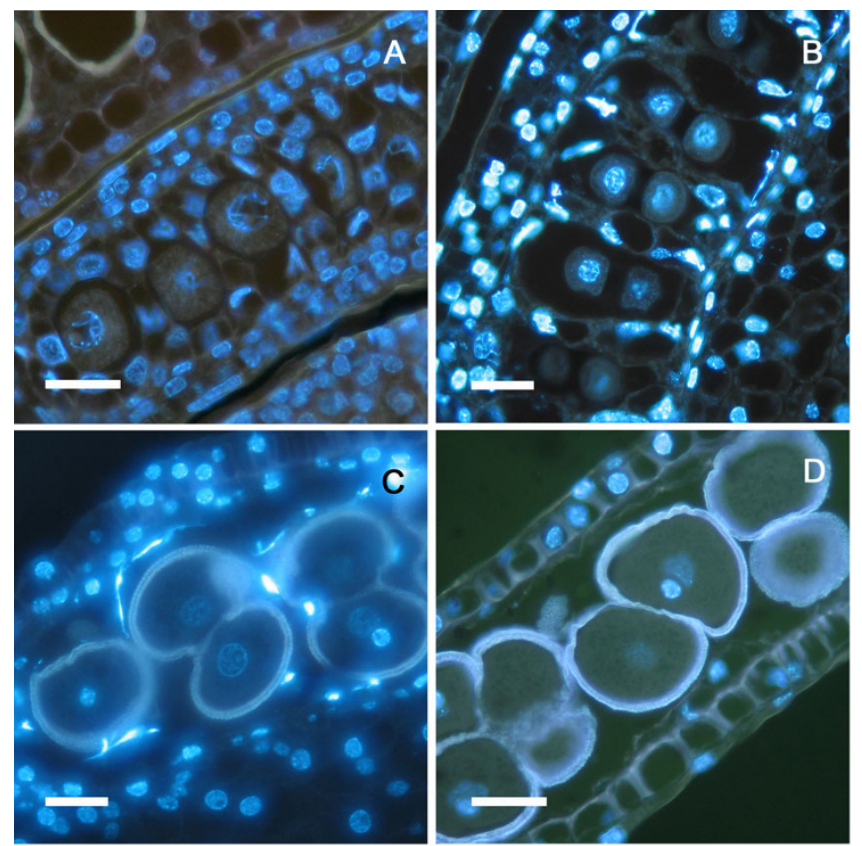

Figure 7

Tapetum degeneration in Annona cherimola. (A) Pollen mother cells in Prophase I and an active tapetum. (B) Dyad phase in enlarged tapetal chambers. (C) Anther, 4 days before anthesis, showing bicellular pollen and degenerated tapetum, with nuclei displaying elongated shapes and chromatin condensation. (D) Tapetum has disappeared in anthers of flowers at the female stage showing mature pollen. Longitudinal $5 \mu \mathrm{m}$ resin sections stained with DAPI. Bar $=20 \mu \mathrm{m}$. together with a extremely high chromatin condensation, revealed by an intense 4',6-diamidino-2-phenylindole (DAPI) fluorescence (Figure 7C), typical features of programmed cell death [28], which have also been found in the tapetal nuclei of other species [29]. At the same time, tapetal cells released their cellular contents that coated the pollen grains to form the pollenkit. At anther dehiscence the tapetum was completely degenerated and had disappeared (Figure 7D).

\section{Discussion}

\section{Pollen development}

Pollen in A. cherimola is shed in groups of four, originating from the same meiotic division and, hence, the same tetrad. Pollen development, however, continues beyond tetrad formation and, although held together, pollen grains are fully mature upon anther dehiscence. Meiosis cytokinesis occurred through the formation of ingrowths of callose that are also found in genera of some primitive angiosperms [30,31] including species of the Magnoliid clade as Magnolia tripetala [32] and Degeneria vitiensis [33] in the Magnoliales, Laurelia novae-zelandiae [34] and Liriodendron tulipifera [35] in the Laurales or Asarum in the Piperales [30] as well as in monocots as Sisyrinchium [36].

Starch accumulated prior to meiosis and the first pollen mitosis and vanished with the onset of these two divisions; this also occurred 6 days before anther dehiscence, preceding the shedding of starchless pollen. The accumulation of starch in PMC has also been reported in other primitive angiosperms, such as Anaxagorea brevipes [37] or Austrobaileya maculata [38], and in other evolutionarily more recent angiosperms $[39,40]$. Vacuolization also follows a conserved pattern $[41,42]$. The cytoplasm enlarges through a first vacuolization and, later on, following the first pollen mitosis, small vacuoles appear as starch builds up.

In most species a dehydration process takes place prior to pollen shedding and starch is hydrolyzed to form sucrose that protects pollen against desiccation [43]. Starchless pollen is the most common pollen type in the angiosperms [44], being more frequent in bicellular than in tricellular pollen $[45,46]$. In A. cherimola, pollen is shed in a highly hydrated stage [47] and this lack of dehydration may explain why the second mitotic division continues in free pollen after pollen shedding, producing a mixed population of bi and tricellular pollen [48]. However, both types of pollen are starchless at anther dehiscence.

\section{Pollen cohesion}

Several reasons could account for the release of pollen in groups of four. In Arabidopsis, failure of different enzymes during the dissolution of the pectic layer that surrounds 
the PMC wall has been reported in two quartet mutants $[10,49]$. In our work the immunolocalization of esterified and non-esterified pectins showed that, although they were clearly present in the PMC wall, the pectins disappeared following tetrad formation. A closer examination of the photographs reveals that the PMC wall, which stains for cellulose, remained beyond the tetrad stage. Interestingly quartet mutants of Arabidopsis also show a defect in the degradation of the PMC wall [10]. Cellulase has also been shown to be involved in the breakdown process of the PMC wall [50] and a delay in its action could lead to this phenomenon. However, this failure does not seem permanent, since 25 days later this wall is completely dissolved. Thus, the permanence of the PMC wall appears as a key factor contributing to pollen grouping as pollen tetrads in A. cherimola, similar to the observations in Arabidopsis mutants. A mixture of enzymes is require to break down the complex PMC wall [2], and a failure of one or more of these enzymes could result in a similar final result.

Different events that take place during the retention of this wall may explain pollen adherence once this wall disappears. The confining of pollen within the tapetal chamber keeping the young microspores in close proximity may contribute to this wall maintenance. Surprisingly, the young microspores are apparently separated from their sibling cells allowing some free movement indicated by the strange $180^{\circ}$ rotation of the pollen aperture sites. Thus, those aperture sites that originally looked outwards rotate inward to face each other. A similar rotation has been reported previously in other Annonaceae [A. glabra and A. montana [22] and Cymbopetalum [23], and also in species of the Poaceae [51]. This distal-proximal microspore polarity transition in development contrasts with the evolutionary shift from a proximal to a distal aperture that has been long regarded as one of the major evolutionary innovations in seed plants [52]. Proximal apertures predominate in the spores of mosses, lycophytes and ferns while distal apertures are more common in extant seed plants including gymnosperms, cycads and early-divergent angiosperms [52]. In fact, species in the Annonaceae with monad pollen are reported to have distal apertures [see [19] for review]. However, a complete study of 25 Annonaceae genera with species that release aggregated pollen showed proximal apertures [16] and, consequently, the distal-proximal transition observed in pollen development of A. cherimola and other Annonaceae $[22,23]$ could represent a widespread situation in this basal family.

Another reason proposed for this permanent binding of pollen in groups of four could be a failure in the synthesis of the callose layer during microspore separation in the tetrad [8]. However, the results shown in this work in A. cherimola indicate that callose is layered following the standard pattern and vanishes later, after meiosis is completed, similar to the way it occurs in Arabidopsis quartet mutants, in which callose dissolution proceeds normally [53]. However, the use of antibodies against callose showed that callose remains for a while in the area where pollen apertures will form hampering the layering of sporopollenin. Callose remnants in this area have also been reported in other Annonaceae and it has been suggested that these remnants pull the pollen grains to undergo the $180^{\circ}$ turning $[22,23]$. In the formation of the pollen wall, callose dissolution occurs concomitantly with the layering of the exine [54] and the formation of the pollen aperture is related to endoplasmic reticulum blocking the deposition of primexine [3]. The callose remnant at the pollen aperture sites has not been investigated in detail in other species and, given the high conservation of pollen ontogeny in angiosperms, this is a topic worthy of a detailed study. Interestingly, in an Arabidopsis mutant lacking the gene responsible for callose synthesis, pollen develops unusual pore structures [55].

Further binding at the aperture sites could follow this initial adhesion process through the observed joint deposition of pollenkit that has also been reported in other species [4]. Thus, two key processes could contribute to holding together the four pollen grains in A. cherimola, the confined space that permits the delay in the dissolution of the PMC wall and the tapetal chamber and pollen rotation that allows the adhesion of the sticky proximal faces by the formation of small pectin bridges. Later, the join deposition of sporopollenin would further strengthen this initial binding.

\section{Biological significance of the pollen dispersal unit}

A failure or delay in the dissolution of the PMC wall and tapetal chamber appears to be a critical step, resulting in the continued proximity of the four microspores produced by meiosis of a single PMC. However, this phenotype could also result from failure in the different enzymes that dissolve the PMC wall. The distribution of this character, together with the information provided by Arabidopsis mutants, shows that this has occurred independently several times during evolution, suggesting that it must provide some evolutionary advantages [8].

The adaptive advantages derived from aggregated pollen have been reviewed recently [6]. The release of aggregated pollen in insect pollinated species could increase pollination efficiency, since more pollen grains could be transferred in a single pollinator visit and, in this sense, a correlation between pollen tetrads and polyads with a high number of ovules per flower has been shown in a survey of the Annonaceae [17]. The release of aggregated pollen is more advantageous in situations where pollinators are infrequent [6] and in situations of short pollen viability and pollen transport periods. A short pollen via- 
bility period has been reported in A. cherimola, $[47,56]$ and a short pollen transport episode is common in several Annonaceae [57] and in other beetle pollinated species of early divergent angiosperm lineages [58].

An additional possible benefit of aggregated pollen is protection against desiccation and entry of pathogens through the thin walls of the pollen aperture sites. Pollen grouped in dyads, tetrads or polyads show a strong proximal reduction of the exine in Annonaceae [59]. A. cherimola pollen is inaperturate and germinates in the proximal face, showing a large area of unprotected intine $[47,60]$. More evolutionarily recent species present a colpus that, in dehydrated pollen, is just a narrow slit protected by loose pollenkit. Only upon hydration, when the pollen faces a wet surface on the stigma, this slit swells developing a wider colpus through which the pollen tube protrudes [61]. Inaperturate pollen does not have this protection from desiccation and the development of inward facing intines may play a role in protecting pollen against desiccation.

\section{Conclusion}

The results obtained in this work support the hypothesis that aggregated pollen could be the result of relatively minor ontogenetic changes beneficial for pollen transfer or/and protection from pollen desiccation. Comparison of the events reported here with those recorded in recent pollen development mutants in Arabidopsis suggests that a simple event along development, the delay in the dissolution of the pollen mother cell wall and tapetal chamber, results in conspicuous morphological changes that lead to the release of pollen in tetrads. A variety of different mutations within the enzymes required to breakdown this wall, may contribute to this common morphology. These changes have occurred and recur in nature and, due to their adaptive advantages for pollen transfer, have been selected during evolution several independent times, representing an example of convergent evolution.

\section{Methods \\ Plant material}

The research was performed on adult A. cherimola, cv. Campas trees of located in a field cultivar collection at the EE la Mayora CSIC, Málaga, Spain. To study the relationship between flower bud length and developmental stages, tagged flower buds were measured sequentially on the trees. Buds were measured twice a week for 8 weeks from leaf unfolding, when the buds were visible but buried under the leaf petiole until anthesis. A. cherimola, as other members of the Annonaceae, presents protogynous dichogamy [62]. The flower opens in the female stage and remains in this stage until the following day in the afternoon when at a precise time, around $6 \mathrm{pm}$. under our environmental conditions, it changes to the male stage: the anthers dehisce, the petals open more widely and the stigmas shrivel [48].

\section{Light microscope preparations}

To follow pollen development, anthers were collected from flower buds of a range of stages, with petals $6,9,12$, 16, 22, 24 and $30 \mathrm{~mm}$ long. Anthers were also collected from flowers one day prior to anthesis and at the female (F) and male (M) stages of mature flowers. The anthers from three flowers of each stage were fixed in glutaraldehyde at $2.5 \%$ in $0.03 \mathrm{M}$ phosphate buffer [63], dehydrated in an ethanol series, embedded in Technovit 7100 (Kulzer \& Co, Wehrheim, Germany), and sectioned at $2 \mu \mathrm{m}$.

Sections were stained with periodic acid-Schiff's reagent (PAS) for insoluble carbohydrates and with PAS/Toluidine Blue for general histological observations [64]. Sections were also stained for cutine and exine with $0.01 \%$ auramine in $0.05 \mathrm{M}$ phosphate buffer [65] and for cellulose with $0.007 \%$ calcofluor in water [66]. Intine and exine were observed with a $3: 1$ mixture of $0.01 \%$ auramine in water and $0.007 \%$ calcofluor in water.

To observe nuclei during pollen development, anthers collected from flowers at the same developmental stages ranging from $9 \mathrm{~mm}$ long to anthesis were also fixed in 3:1 (V1/V2) ethanol-acetic acid, embedded as described above, sectioned at $5 \mu \mathrm{m}$ and stained with a solution of $0.25 \mathrm{mg} / \mathrm{ml}$ of $4^{\prime}, 6$-diamidino-2-phenylindole (DAPI) and $0.1 \mathrm{mg} / \mathrm{ml} p$-phenylenediamine (added to reduce fading) in $0.05 \mathrm{M}$ Tris ( $\mathrm{pH} \mathrm{7.2)}$ for $1 \mathrm{hr}$ at room temperature in a light-free environment [67]. Preparations were observed under an epifluorescent Leica DM LB2 microscope with 340-380 and LP 425 filters for auramine, calcofluor, and DAPI.

For the study of pollen morphology and pollen size, dehisced anthers were sieved through a $0.26 \mathrm{~mm}$ mesh sieve and the pollen was placed in glacial acetic acid for acetolysis. Pollen grains were transferred to a mixture of 9:1 acetic anhydride:concentrated sulphuric acid at $65^{\circ} \mathrm{C}$ for 10 minutes, then washed with glacial acetic acid and washed again three times with water following a modification of the method by Erdtman (1960) [68].

\section{Scanning electron microscopy}

Pollen for scanning electron microscopy (SEM) was fresh dried with silica gel and directly attached to SEM stubs using adhesive carbon tabs and observed with a JSM-840 scanning electron microscope (JEOL) operated at $10 \mathrm{kV}$.

\section{Immunocytochemistry}

Immunocytochemistry was performed on Technovit 8100 (Kulzer \& Co, Wehrheim, Germany) embedded semithin sections and revealed by fluorochromes, as described pre- 
viously $[69,70]$. Anthers from three flowers per developmental stage with petals $6,9,12,16,22,24$ and $30 \mathrm{~mm}$ long and at anthesis were fixed in $4 \%$ paraformaldehyde in phosphate buffered saline (PBS) at $\mathrm{pH} 7.3$ overnight at $4^{\circ} \mathrm{C}$, dehydrated in an acetone series, embedded in Technovit 8100 (Kulzer), polymerized at $4{ }^{\circ} \mathrm{C}$ and sectioned at $2 \mu \mathrm{m}$. Sections were placed in a drop of water on a slide covered with 3-Aminopropyltrietoxy-silane $2 \%$ and dried at room temperature.

Different antibodies were used to localize specific cell components: an anti-RNA mouse monoclonal antibody, D44 [71,72], for total RNA detection; JIM5 and JIM7 rat monoclonal antibodies (Professor Keith Roberts, John Innes Centre, Norwich, UK) which respectively recognize low and high-methyl-esterified pectins [73] for localization of pectins; and an anti-callose mouse monoclonal antibody (Biosupplies, Parkville, Australia) for callose.

Sections were incubated with PBS for 5 minutes and later with $5 \%$ bovine serum albumin (BSA) in PBS for 5 minutes. Then, different sections were incubated for one hour with the primary antibodies: JIM5, JIM7, and anti-RNA undiluted and anti-callose diluted 1/20 in PBS. After three washes in PBS, the sections were incubated for 45 minutes in the dark with the corresponding secondary antibodies (anti-rat, for JIM5 and JIM7, and anti-mouse, for antiRNA and anti-callose) conjugated with Alexa 488 fluorochrome (Molecular Probes, Eugene, Oregon, USA) and diluted $1 / 25$ in PBS. After three washes in PBS and water, the sections were mounted in Mowiol 4-88 (Polysciences), examined with a Zeiss Axioplan epifluorescent microscope, and photographed with a CCD Digital Leica DFC 350 FX camera.

\section{Authors' contributions}

JL performed most of the experimental analyses, PST had an active contribution to the immunocytochemistry assays, MCR designed and discussed the immunocytochemistry essays, JIH participated in the design of the experiments, $\mathrm{MH}$ coordinated the study. All authors contributed to the draft and read and approved the final manuscript.

\section{Acknowledgements}

Financial support for this work was provided by the Spanish Ministry of Science and Innovation (Project Grants AGL2004-02290/AGR, AGL2006I3529-C0I, AGL2007-60 I30/AGR, AGL2008-04255 and BFU2008-00203), GIC-Aragón 43, Junta de Andalucía (AGR2742) and the European Union under the INCO-DEV program (Contract 0I5100). JL. was supported by a grant of the Junta de Andalucía. The authors thank K. Pinney for helpful suggestions to improve the manuscript.

\section{References}

I. McCormick S: Control of male gametophyte development. Plant Cell 2004, 16:SI42-SI53.
2. Scott RJ, Spielman M, Dickinson HG: Stamen development: primordium to pollen. In The molecular biology and biotechnology of flowering Edited by: Jordan BR. CAB International, Wallingford, UK; 2006:298-33I.

3. Blackmore S, Wortley AH, Skvarla JJ, Rowley JR: Pollen wall development in flowering plants. New Phytologist 2007, 174:483-498.

4. Pacini E, Franchi GG: Pollen grain sporoderm and types of dispersal units. Acta Societatis Botanicorum Poloniae 1999, 68:299-305.

5. Walker JW, Doyle JA: Bases of angiosperm phylogeny - palynology. Annals of the Missouri Botanical Garden 1975, 62:664-723.

6. Harder L, Johnson S: Function and evolution of aggregated pollen in angiosperms. International Journal of Plant Sciences 2008, 169:59-78.

7. Pacini E, Franchi GG, Hesse M: The tapetum - its form, function, and possible phylogeny in embryophyta. Plant Systematics and Evolution 1985, 149:155-185.

8. Blackmore S, Crane PR: The systematic implications of pollen and spore ontogeny. In Ontogeny and Systematics Edited by: Humphries CJ. British Museum (Natural History), London, UK; 1988:83-II5.

9. Preuss D, Rhee SY, Davis RW: Tetrad analysis possible in Arabidopsis with mutation of the QUARTET (QRT) genes. Science 1994, 264: |458-| 460.

10. Rhee SY, Osborne E, Poindexter PD, Somerville CR: Microspore separation in the quartet 3 mutants of Arabidopsis is impaired by a defect in a developmentally regulated polygalacturonase required for pollen mother cell wall degradation. Plant Physiology 2003, 133:1 I70-1180.

II. APG II: An update of the Angiosperm Phylogeny Group classification for the orders and families of flowering plants: APG II. Botanical Journal of the Linnean Society 2003, I 41:399-436.

12. Soltis DE, Soltis PS, Endress PK, Chase MW: Phylogeny and evolution of angiosperms Sinauer Associates Incorporated, Sunderland, Massachusetts, USA; 2005.

13. Doyle JA, Le Thomas A: Cladistic analysis and pollen evolution in Annonaceae. Acta Botanica Gallica 1994, 141:149-170.

14. Doyle JA, Le Thomas A: Phylogeny and geographic history of Annonaceae. Geographie Physique et Quaternaire 1997, 5 I:353-36I.

15. Pirie MD, Vargas MPB, Botermans M, Bakker FT, Chatrou LW: Ancient paralogy in the cpDNA trnL-F region in Annonaceae: implications for plant molecular systematics. American Journal of Botany 2007, 94:1003-1016.

16. Walker JW: Unique type of angiosperm pollen from the family Annonaceae. Science 1971, 172:565-567.

17. Walker JW: Pollen morphology, phytogeography and phylogeny of the Annonaceae. Contributions of the Gray Herbarium of Harvard University 1971, 202: I- I32.

18. Doyle JA, Le Thomas A: Significance of palynology for phylogeny of Annonaceae: experiments with removal of pollen characters. Plant Systematics and Evolution 1997, 206: I33-159.

19. Le Thomas A: Ultrastructure characters of the pollen grains of African Annonaceae and their significance for the phylogeny of primitive angiosperms (first part). Pollen et Spores 1980, 22:267-342.

20. Le Thomas A: Ultrastructure characters of the pollen grains of African Annonaceae and their significance for the phylogeny of primitive angiosperms (second part). Pollen et Spores 198I, 23:5-36.

21. Su YCK, Saunders RMK: Pollen structure, tetrad cohesion and pollen-connecting threads in Pseuduvaria (Annonaceae). Botanical Journal of the Linnean Society 2003, I 43:69-78.

22. Tsou CH, Fu YL: Tetrad pollen formation in Annona (Annonaceae): proexine formation and binding mechanism. American Journal of Botany 2002, 89:734-747.

23. Tsou CH, Fu YL: Octad pollen formation in Cymbopetalum (Annonaceae): the binding mechanism. Plant Systematics and Evolution 2007, 263:13-23.

24. Barrett S: Major evolutionary transitions in flowering plant reproduction: an overview. International Journal of Plant Sciences 2008, 169: I-5.

25. Higuchi $\mathrm{H}$, Utsunomiya $\mathrm{N}$ : Floral differentiation and development in cherimoya (Annona cherimola Mill.) under warm (30/ 25 degrees $C$ ) and cool (20/15 degrees $C$ ) day/night temperatures. Journal of the Japanese Society for Horticultural Science 1999, 68:707-716 
26. Periasamy K, Kandasamy MK: Development of the anther of Annona squamosa L. Annals of Botany 198I, 48:885-893.

27. Tsou CH, David J: Comparative development of aseptate and septate anthers of Annonaceae. American Journal of Botany 2003, 90:832-848.

28. Wu H, Cheung AY: Programmed cell death in plant reproduction. Plant Molecular Biology 2000, 44:267-28I.

29. Testillano PS, Corredor E, Solís MT, Chakrabarti N, Raska I, Risueño MC: Changes in nuclear architecture and DNA methylation pattern accompany the developmental programmed cell death of the tapetum. Proceedings of the 6th. Plant Genomics European Meeting. Tenerife, Spain 2007:9-10.

30. Furness CA, Rudall PJ, Sampson FB: Evolution of microsporogenesis in angiosperms. International Journal of Plant Sciences 2002, 163:235-260.

3I. Nadot S, Furness CA, Sannier J, Penet L, Triki-Teurtroy S, Albert B, Ressayre A: Phylogenetic comparative analysis of microsporogenesis in angiosperms with a focus on monocots. American journal of Botany 2008, 95: | 426-1436.

32. Farr $\mathrm{CH}$ : Cell division by furrowing in Magnolia. American Journal of Botany 1918, 5:379-395.

33. Dahl AO, Rowley JR: Pollen of Degeneria vitiensis. Journal of the Arnold Arboretum, Harvard University 1965, 46:308-323.

34. Sampson FB: Cytokinesis in pollen mother cells of angiosperms, with emphasis on Laurelia-novae-zelandiae (Monimiaceae). Cytologia 1969, 34:627-634.

35. Guzzo F, Baldan B, Bracco F, Mariani P: Pollen development in Liriodendron-tulipifera - some unusual features. Canadian Journal of Botany 1994, 72:352-358.

36. Farr $\mathrm{CH}$ : Quadripartition by furrowing in Sisyrinchium. Bulletin of the Torrey Botanical Club 1922, 49:5I-6I.

37. Gabarayeva NI: Pollen wall and tapetum development in Anaxagorea brevipes (Annonaceae) - sporoderm substructure, cytoskeleton, sporopollenin precursor particles, and the endexine problem. Review of Palaeobotany and Palynology 1995, 85: $123-152$.

38. Zavada M: Pollen wall development of Austrobaileya maculata. Botanical Gazette 1984, I 45: I I-2 I.

39. Xiang-Yuan X, Demason DA: Relationship between male and female gametophyte development in rye. American Journal of Botany 1984, 71:1067-1079.

40. Pacini E, Franchi GG: Amylogenesis and amylolysis during pollen grain development. In Sexual reproduction in higher plants Edited by: Cresti M, Gori P, Pacini E. Springer, Berlin, Heidelberg, New York; 1988:181-186.

41. Maheshwari P: An introduction to the embryology of angiosperms McGraw-Hill, New York, USA; 1950.

42. Bedinger P: The remarkable biology of pollen. Plant Cell 1992 4:879-887.

43. Franchi GG, Bellani L, Nepi M, Pacini E: Types of carbohydrate reserves in pollen: localization, systematic distribution and ecophysiological significance. Flora 1996, 191:143-159.

44. Grayum MH: Evolutionary and ecological significance of starch storage in pollen of the Araceae. American Journal of Botany 1985, 72:1565-1577.

45. Brewbaker JL: Distribution and phylogenetic significance of binucleate and trinucleate pollen grains in angiosperms. American Journal of Botany 1967, 54:1069-1083.

46. Baker HG, Baker I: Starch in angiosperm pollen grains and its evolutionary significance. American Journal of Botany 1979, 66:591-600.

47. Lora J, Oteyza MAP, Fuentetaja P, Hormaza Jl: Low temperature storage and in vitro germination of cherimoya (Annona cherimola Mill.) pollen. Scientia Horticulturae 2006, 108:91-94.

48. Lora J, Herrero M, Hormaza Jl: The coexistence of bicellular and tricellular pollen in Annona cherimola Mill. (Annonaceae): Implications for pollen evolution. American Journal of Botany 2009, 96:802-808

49. Francis KE, Lam SY, Copenhaver GP: Separation of Arabidopsis pollen tetrads is regulated by QUARTETI, a pectin methylesterase gene. Plant Physiology 2006, I 42:1004-1013.

50. Neelam A, Sexton R: Cellulase (endo beta-I,4 glucanase) and cell-wall breakdown during anther development in the sweet pea (Lathyrus odoratus L.): isolation and characterization of partial cDNA clones. Journal of Plant Physiology 1995, 146:622-628.
51. Rowley JR: Formation of the pore in pollen of Poa annua. In Pollen physiology and fertilization Edited by: Linskens HF. North-Holland Publishing Company, Amsterdam, Netherlands; 1964:59-69.

52. Rudall PJ, Bateman RM: Developmental bases for key innovations in the seed-plant microgametophyte. Trends in Plant Science 2007, I 2:3 I7-326.

53. Rhee SY, Somerville CR: Tetrad pollen formation in quartet mutants of Arabidopsis thaliana is associated with persistence of pectic polysaccharides of the pollen mother cell wall. Plant Journal 1998, 15:79-88.

54. Testillano PS, Fadon B, Risueño MC: Ultrastructural localization of the polysaccharidic component during the sporoderm ontogeny of the pollen grain. Review of Paleobotany and Palynology 1995, 85:53-62.

55. Enns LC, Kanaoka MM, Torii KU, Comai L, Okada K, Cleland RE: Two callose synthases, GSLI and GSL5, play an essential and redundant role in plant and pollen development and in fertility. Plant Molecular Biology 2005, 58:333-349.

56. Rosell P, Herrero M, Sauco VG: Pollen germination of cherimoya (Annona cherimola Mill.). In vivo characterization and optimization of in vitro germination. Scientia Horticulturae 1999, $81: 251-265$

57. Ratnayake RMCS, Gunatilleke IAUN, Wijesundara DSA, Saunders RMK: Reproductive biology of two sympatric species of Polyalthia (Annonaceae) in Sri Lanka. I. Pollination by curculionid beetles. International Journal of Plant Sciences 2006, 167:483-493.

58. Davis CC, Endress PK, Baum DA: The evolution of floral gigantism. Current Opinion in Plant Biology 2008, I I:49-57.

59. Le Thomas A, Morawetz W, Waha M: Pollen of paleo- and neotropical Annonaceae: definition of the aperture by morphological and functional characters. In Pollen and Spores: Form and Function Edited by: Blackmore S, Ferguson IK. Academic Press, London, UK; 1986:375-388

60. Rosell P, Sauco VG, Herrero M: Pollen germination as affected by pollen age in cherimoya. Scientia Horticulturae 2006, I09:97-100.

61. Heslop-Harrison Y, Heslop-Harrison J: Germination of monocolpate angiosperm pollen: evolution of the actin cytoskeleton and wall during hydration, activation and tube emergence. Annals of Botany 1992, 69:385-394.

62. Gottsberger G: Pollination and evolution in Neotropical Annonaceae. Plant Species Biology 1999, 14:143-152.

63. Sabatini DD, Bensch K, Barrnett RJ: Cytochemistry and electron microscopy - preservation of cellular ultrastructure and enzymatic activity by aldehyde fixation. Journal of Cell Biology 1963, 17:19-58.

64. Feder N, O'Brien TP: Plant microtechnique: some principles and new methods. American Journal of Botany 1968, 55:123-142.

65. Heslop-Harrison Y: Pollen-stigma interaction - pollen-tube penetration in Crocus. Annals of Botany 1977, 41:913-922.

66. Hughes J, McCully ME: Use of an optical brightener in study of plant structure. Stain technology 1975, 50:319-329.

67. Williams JH, Friedman WE, Arnold ML: Developmental selection within the angiosperm style: Using gamete DNA to visualize interspecific pollen competition. Proceedings of the National Academy of Sciences USA 1999, 96:9201-9206.

68. Erdtman G: The acetolysis method. Svensk Botanisk Tidskrift 1960 , 54:56I-564

69. Satpute GK, Long H, Seguí-Simarro JM, Risueño MC, Testillano PS: Cell architecture during gametophytic and embryogenic microspore development in Brassica napus L. Acta Physiologia Plantarum 2005, 27:665-674

70. Solís MT, Pintos B, Prado MJ, Bueno MA, Raska I, Risueño MC, Testillano PS: Early markers of in vitro microspore reprogramming to embryogenesis in olive (Olea europaea L.). Plant Science 2008, I 74:597-605

7I. Eilat D, Fischel R: Recurrent utilization of genetic elements in $\checkmark$ regions of antinucleic acid antibodies from autoimmune mice. Journal of Immunology 1991, 1 47:361-368.

72. Mena CG, Testillano PS, Gonzalez-Melendi P, Gorab E, Risueño MC: Immunoelectron microscopy detection of RNA in plant nucleoli. Experimental Cell Research 1994, 21 2:393-408.

73. Knox JP: The use of antibodies to study the architecture and developmental regulation of plant cell walls. International Review of Cytology 1997, I71:79-120. 